\title{
Sintagma: Përkufizimi, Ndërtimi Dhe Karakteristikat Dalluese Të Saj Krahasuar Me Togfjalëshin
}

\author{
Phd. Joana Taci* \\ University “Eqrem Çabej”, Gjirokaster, Faculty of Social Sciences, Department of Foreign Languages, Albania \\ *Corresponding Author: Phd. Joana Taci, University "Eqrem Çabej”, Gjirokaster, Faculty of Social \\ Sciences, Department of Foreign Languages, Albania
}

\begin{abstract}
This article aims at shedding light on the revolution the Albanian linguistic studies and researches underwent after the introduction of the linguistic term "phrase". After 1950' with the launching of Noam Chomsky "Syntactic Structure" the phrase was considered as the linguistic basic unit in the construction and distribution of larger meaningful strings known as sentence. It was not until recently that this term was embraced by our scholars and researchers as a mean of completely contradicting the structuring of a sentence in terms of word groups "togfjalesh". Pursuant to, this article focuses on the construction and distribution of phrases, their advantages as compared to the drawbacks the analysis of a sentence in terms of word groups displays. As so, word groups are considered to be a combination of only two lexical and meaningful items; they do not display any hierarchical internal structure; they completely exclude coordination; and they also lack the principle of Head and Binary Relations.
\end{abstract}

Key Words: phrase, word groups, linguistic unit, Head principle, Binary principle, generative linguistics

\section{INTRODUCTION}

Sipas konceptit gjenerativist mbi ndërtimet gjuhësore, sintagma (phrase) është konceptuar si “një bashkësi e pafundme frazash të ndërtura nga një numër i fundëm elementësh bazë", ku me elementë bazë do të kuptohen fonemat dhe morfemat ${ }^{1}$. Nisur nga ky përkufizim, si njësia më e rëndësishme në përshkrimin e gjuhëve njërëzore është pranuar "phrase/fraza" (anglisht) e cila përbën një njësi të një niveli përfaqësimi më të lartë se ai fonemor dhe morfemor. Termi sintagmë/phrase në vetvete është një përfaqësim $i$ termit më të hershëm "përbërës" i përdorur për herë të parë më 1933 nga distribucionalistët amerikanë ${ }^{2}$ të cilët patën si qëllim të përcaktonin ndërtimin e fjalive të një korpusi me pikënisje përbërësit e drejtpërdrejtë mbi bazën e varësisë dhe lidhjes së ngushtë të elementëve. Me përbërës të drejtpërdrejtë do të kuptohej secili prej elementeve që rezulton nga ndarja e parë e një njësie gjuhësore në pjesë. Ose ndryshe përbërësi i drejtpërdrejtë është njësi gjuhësore që bën pjesë në një ndërtim më të gjerë, i formuar edhe ky nga përbërës më të vegjël. Termi aktual sintagme/phrase nuk identifikohet vetem me Chomskin, pasi atë e gjejmë edhe te Sosyri. Ky i fundit, duke u nisur nga përkufizimi i njohjes gjuhësore të individëve si produkt i shoqërisë, e përkufizon termin frazë si "kombinime me të cilat folësi bën të ditura (shkodon) mendimet e veta". Pra Sosyri frazën e sheh si njësi të ligjerimit, ndërsa Chomsky e trajton atë si njësi themelore të gjuhës. Përsa i përket gjuhës shqipe, për vetë faktin se përdorimi i termit frazë do të keqinterpretohej si fjali ose periudhe, është preferuar përdorimi i termit "sintagmë”. Për ta kuptuar më mirë shpjegojmë se termi frazë në gjuhën shqipe është përdorur për herë të parë nga M. Domi $(1964)^{4}$ duke nënkuptuar dy ose më shumë fjali të bashkuara me mjete të ndryshme sintaksore. M. Totoni $(2000)^{5}$ e përkufizon frazën si njësi sintaksore të ligjërimit të realizuar në një kontekst a situatë të karakterizuar nga kuptimi i plotë dhe intonacioni i mbaruar. Pra, sipas këtij studiuesi ajo përfaqëson fjalitë e thjeshta, pasi të përbërat konsiderohen

\footnotetext{
${ }^{1}$ Chomsky N. Syntactic Structures, 2002 fq 18-33

${ }^{2}$ Dhima Th. "Çështje të sintaksës në gjuhën shqipe” Art. "Rreth analizës sintaksore të fjalisë”, Tiranë,2013, fq. 29

${ }^{3}$ Chomsky N. Le strutture della sintassi (variant i versionit anglisht Syntactic Structures), 1974 fq. VII-XXXI

${ }^{4}$ Dhima Th., Disa veçori të frazës shqipe në këndvështrimin e gjuhësisë së sotme, Seminari i Albanologjisë, Ohër, 2007

${ }^{5}$ Po aty
} 
periudha. Vitet e fundit, falë ndikimit revolucionarizues të gjuhësisë gjenerative, me termin frazë/sintagmë nënkuptohet njësia ndërtimore, kuptimore që qëndron e pozicionuar midis fjalës (e cila kryen funksion sintaksor) dhe fjalisë (e cila përmban kuptim). Në këtë kontekst, ajo përfaqëson një njësi me madhësi të pacaktuar duke përfshirë si një fjalë të vetme ashtu edhe një fjali. Gjithashtu, fraza/sintagma konceptohet si njësi ndërtimore e kuptimore e cila kur përputhet me grupin kuptimor ka intonacionin e vet që është pjesë e lakores melodike të fjalisë. Për të kuptuar më tepër se çfarë përfaqësojnë frazat/sintagmat, kufijtë e tyre si dhe për të specifikuar se cilat kombinime hierarkike brenda strukturës së një fjalie do të pranohen si të tilla studiuesit Adger ${ }^{6}$, Heageman ${ }^{7}$ dhe Radford ${ }^{8}$ propozojnë praktikat e mëposhtme të testimit.

\section{KoHEZIONI SEMANTIK}

Shembull.

2.a. That bottle of water might have been broken.

\section{2.b Ajo shishe uji mund të ketë qenë e thyer.}

Vargu i fjalëve that bottle of water/ajo shishe uji ka një kohesion semantik të cilin nuk e gjejmë te vargu of water might/uji mund. Vargu i parë në krahasim me vargun e dytë përmban kuptim, por nuk mund të pretendojmë se plotësia kuptimore e tyre ështe barazvlefshme me atë të fjalisë.

\section{FUNKSIONI SINTAKSOR I NJËJTË ME FUNKSIONIN SINTAKSOR TË NJË FJALE TË VETME}

Një varg fjalësh, ashtu si një fjalë e vetme, mund të luajë të njëjtin rol dhe të kryejë të njëjtin funksion në fjali.

\section{Shembull}

3.a The student protested violently.

3.b The first year student protested violently.

3.c Studenti kishte protestuar fuqimisht.

3.d Studenti i vitit të parë kishte protestuar fuqimisht.

\section{LËVIZJA E FRAZAVE BRENDA FJALISË}

Folësit e lindur të një gjuhe janë në gjendje të dallojnë nëse një varg fjalësh përbën një frazë edhe në rastet kur ky term është i panjohur për ta.

\section{Shembull}

4.a Many students participated in the cultural activities.

In the cultural activities participated many students.

* Many participated students in the cultural activities (jogramatikore)

4.b Shumë studentë morën pjesë në aktivitetet kulturore.

Në aktivitetet kulturore morën pjesë shumë studentë.

* Shumë morën pjesë studentë në aktivitetet kulturore.(jogramatikore)

Vargjet e natyrshme të fjalëve mund t'i zhvendosim, pa ndikuar në gramatikalitetin e fjalisë, nga një pikë e fjalisë në një tjetër. (E pranuar kjo për shqipen në tërësi dhe për ndërtime të veçanta dhe të kufizuara të anglishtes)

\section{SHQIPTIMI I VEÇUAR.}

Një frazë mund të shqiptohet e veçuar si një thënie më vete e painkuadruar në përbërjen e fjalisë. Këtu përshijmë ndërtimet pyetëse të anglishtes të njohura si "wh-questions" dhe ato të shqipes të ndërtuara me ndihmën e përemrave pyetës Kush? Kujt? Kë? etj.

\footnotetext{
${ }^{6}$ Adger D., Core Syntax. A minimalist approach, 2002, fq. 48-53

${ }^{7}$ Heageman L., Introduction to government and binding theory, 1991, fq. 23-31

${ }^{8}$ Radford A., Minimalist Syntax. Exploring the structure of English, 2004, fq 38-39 
Shembull

5.a Jill will meet his fiance at the castle. (Fjalia bazë)

5.b Whom will Jill meet at the castle?

His fiance - përbërës emëror, kundrinor i drejtë

5.c Maria do të takojë të fejuarin në kështjellë.

5.d K Kë do të takojë Maria në kështjellë

Të fejuarin - përbërës emëror kundrinor i drejtë

\section{MOSNDËRPRERJA.}

Nëse duam të shtojmë një përcaktues kohor si "djelyesterday" në përbërjen e fjalisë, atë mund ta pozicionojmë kudo, por jo midis përbërësve të një fraze.

\section{Shembull}

6.a Many students participated yesterday in the cultural activities.

* Many yesterday students participated in the cultural activities.

6.b Dje shumë studentë morën pjesë në aktivitetet kulturore.

* Shumë dje studentë morën pjesë në aktivitetet kulturore.

\section{ZËVENDËSIMI ME NJË PROFORMË.}

Si proformë do të shërbejë një përemër vetor si dhe ndajfoljet atje, këtu etj, të cilat mund të përdoren në vend të grupeve emërore ose parafjalore.

\section{Shembull}

7.a The ambassador of USA greeted all the students.

$H e$ greeted all the students.

7.b Ambasadori i USA përshëndeti të gjithë studentët.

$A i$ përshëndeti të gjithë studentët.

\section{BASHKËRENDITJA.}

Vetëm sintagmat e të njëjtit tip mund të bashkërenditen.

\section{Shembull}

8.a Our friends and our colleagues are all invited in our wedding ceremony.

8.b Shokët dhe kolegët tanë janë të gjithë të ftuar në ceremoninë tonë të dasmës.

Në gjuhën shqipe termi sintagmë përfaqëson një term të përdorur shumë më herët se zbatimi i gramatikës gjenerative. Ky term përmendet për herë të parë më 1959 nga S. Prifti kur thotë se "njësitë sintaksore quhen sintagma apo togje fjalësh",. Me termin sintagmë S. Prifti jep idenë e grupit të fjalëve që ka një bërthamë e që mund të zgjerohet me tej me elemente të tjerë. Mirëpo, ky koncept tek ai është shumë i gjerë, pasi përfshin edhe fjalët e përbëra. Gjithashtu ndarja që i bëhet fjalisë nga S. Prifti në sintagma afron më shumë me ndarjen në togfjalësh të gjuhësisë tradicionale.

Nga ana tjetër termi togfjalësh i gjuhësisë tradicionale ka hyrë në sintaksën e gjuhës shqipe që nga viti 1968 në një kumtesë të mbajtur nga S. Floqi në Konferencën e Dytë Albanologjike ${ }^{10}$. Analiza e fjalisë në togfjalësh përbën një kontribut të padiskutueshëm në gjuhën shqipe, pasi jo vetëm që i përshtatet kësaj gjuhe, por edhe disiplinoi ndërgjegjen tonë gramatikore me nocion e grupit te fjalëve se midis kategorisë së fjalës dhe fjalisë ka edhe një kategori të ndërmjetme të quajtur togfjalësh. Pra, me fjalë të tjera termi "togfjalësh" i gjuhës shqipe është përkufizuar si "njësia sintaksore dhe strukturore e

\footnotetext{
${ }^{9}$ Dhima Th. "Çështje të sintaksës në gjuhën shqipe” Art. "Rreth analizës sintaksore të fjalisë”, Tiranë,2013, fq. 32

${ }^{10}$ Dhima Th. "Çёshtje të sintaksës në gjuhën shqipe" Art. "Probleme të njësive sintaksore (Togfjalëshi dhe sintagma)", Tiranë,2013, fq. 13.
} 
përftuar gjatë ligjërimit nga bashkimi gramatikor $i$ dy a më shumë fjalëve kuptimplota"11. Nga ana tjetër teoria e togfjalëshit ngre probleme si në planin teorik dhe në atë praktik të analizës së fjalisë, gjë që e bën të nevojshme zëvendësimin e këtij termi me atë të sintagmës. Sqarojmë se në gjuhën shqipe nuk kemi të bëjmë vetëm me një zëvendësim termash, por më saktë me një rikonceptim të njësisë bazë të strukturës së fjalisë duke pasqyruar përparësitë që sintagma (krahasuar më togfjalëshin) ka.

1. Togfjalëshi karakterizohet nga dygjymtyrësia, pra ai formohet si rezultati i bashkimit kuptimor dhe gramatikor i dy fjalëve, jo çfarëdo, por fjalë shënuese ose kuptimplota. Përkundrazi, vëllimi i sintagmës varion nga një fjalë e vetme në një fjali, struktura e së cilës ka karakter binar dukë përfshirë dy kategori sintaksore dhe jo dy gjymtyrë. Gjithashtu theksojmë se në përbërjen e sintagmës pranohen si fjalët shënuese (kuptimplota) edhe ato joshënuese (jokuptimplota).

\section{Shembull}

9.a The concert ended sucessfully.

9.b Koncerti përfundoi me sukses.

$\mathbf{S E}$ - Koncerti; the concert - përbëhet nga një fjalë e vetme.

Togfjalëshat: koncerti përfundoi; përfundoi me sukses; the concert ended; ended sucessfully.

Sintagmat: SE ( the concert; koncerti) SF (ended sucessfully; përfundoi me sukses) $\mathrm{SNd}_{\text {anglisht }}$ (sucessfully) $\mathrm{SP}_{\text {shqip }}$ (me sukses)

Teoria e sintagmave pranon si përbërës të sintagmave edhe fjalë joshënuese, si: numërori, përemri ${ }^{12}$, nyja e cila është pjesë përbërëse e SE dhe parafjala, e cila jo vetëm që është përbërëse e SP por edhe kokë e saj. Në këtë kontekst, për të vërtetur më tej faktin se elemetët përbërës të sintagmave janë edhe fjalët joshënuese, vlen të përmendim praninë e sintagmave funksionale si SEPT (Sintagma e Eptimit) dhe SK (Sintagma Komplomentuese).

2. Sintagmat kanë strukturë të brendshme të organizuar në mënyrë hierarkike, duke u nisur nga sintagma maksimale (fjalia) dhe duke mbëritur shkallë - shkallë te niveli më i ulët ai i kokës së sintagmës sipas rishkrimit të mëposhtëm:

$$
\begin{array}{rl}
\mathbf{F j} \rightarrow \mathbf{S E}+\mathbf{S F} & \mathbf{S} \rightarrow \mathbf{N P}+\mathbf{V P} \\
\mathbf{S E} \rightarrow \text { Spec }+\mathbf{E} & \mathbf{N P} \rightarrow \mathbf{S p e c}+\mathbf{N} \\
\mathbf{S F} \rightarrow \mathbf{F}+\mathbf{S E}+\mathbf{S P} & \mathbf{V P} \rightarrow \mathbf{V}+\mathbf{N P} \\
\mathbf{S E} \rightarrow \text { Spec }+\mathbf{E} & \mathbf{N P} \rightarrow \mathbf{S p e c}+\mathbf{N}
\end{array}
$$

Përkundrazi togfjalëshi shënon bashkime dyshe të fjalëve pa zbuluar strukturën e tyre të brendshme. Te togfjalëshi e njëjta fjalë mund të jetë element përbërës i një, dy ose më shumë kombinimeve togfjalëshore, ndërsa te sintagma një kokë e dhënë formon sintagmë vetëm një herë.

\section{Shembull}

10.a Nga dashuria e madhe për Atdheun buronin ato fjalë zemre për mërgimtarët.

Kjo fjali do të zbërthehej në togfjalëshat e mëposhtëm: a) nga dashuria e madhe; b) dashuria për atdheun; c) buronin ato fjalë; d) ato fjalë zemre; e) ato fjalë për mërgimtarët.

Pra togfjalëshat e mësipërm janë formuar duke i lidhur fjalët dy e nga dy në mënyrë drejtvizore, pa shfaqur lidhjet hierarkike të tyre.

Sintagmat e fjalisë së mësipërme janë: SE - nga dashuria e mashe për atdheun; SF- buronin ato fjalë zemre SE - ato fjalë zemre SP - për mërgimtarët

Kjo e fundit dëshmon se, togfjalëshi përbën një nga mundësite e realizimit të sintagmës dhe jo një njësi sintaksore të veçantë.

\footnotetext{
${ }^{11}$ Gramatika e gjuhës shqipe I, Akademia e Shkencave e Republikës së Shqipërisë, 2002

${ }^{12} \mathrm{Në} \mathrm{gjuhën} \mathrm{shqipe} \mathrm{përemrat} \mathrm{dhe} \mathrm{numërorët} \mathrm{nuk} \mathrm{përfshihen} \mathrm{në} \mathrm{togfjalësh,} \mathrm{pasi} \mathrm{ato} \mathrm{nuk} \mathrm{janë} \mathrm{fjalë} \mathrm{shënuese}$ Gjithashtu këto pjesë të ligjëratës nuk përfshihen as në teorinë e sintagmave duke mos dalë si sintagma më vete. Ndryshe nga teoria e togfjalëshit në teorinë e sintagmës numërorët dhe përemrat pranohen si koka të sintagmës emërore. (Dhima Th. "Çështje të sintaksës në gjuhën shqipe" Art. "Probleme të njësive sintaksore (togfjalëshi dhe sintagma", Tiranë,2013, fq. 18,19)
} 
3. Teoria e togfjalëshit përjashton lidhjet me bashkërenditje për arsye se uniteti gramatikor dhe kuptimor i togfjalëshit zbulohet vetëm në lidhjet me nënrenditje. Përparësia e analizës në sintagma është se krahas sintagmave me lidhje varësie analizohen edhe sintagmat me bashkërenditje, tek të cilat dallojmë dy a më shumë sintagma të një lloji të lidhura me lidhjen e bashkërenditjes.

\section{Shembull}

11.a $\quad n \ddot{e} f$ shat dhe në qytet; in the village and in the city $\rightarrow$ përbën sintagmën parafjalore dominuese të përbërë nga:

$\mathbf{S P} \rightarrow n \ddot{e}$ fshat; in the village

$\mathbf{S P} \rightarrow n \ddot{e}$ qytet; in the city

Dallimi midis sintagmave me lidhje varësie dhe atyre me lidhje bashkërenditjeje është se në të parat përbërësit e sintagmave i përkasin kategorive të ndryshme, ndërsa në të dytat i përkasin të njëjtës kategori së cilës i përket edhe sintagma dominuese.

4.Një ndër përparësitë e analizës së fjalisë në sintagma është edhe shpjegimi i fjalive njëkryegjumtyrëshe dhe fjalive të paplota duke pranuar ekzistencën e sintagmës zero.

\section{Shembull}

11.b Nisemi. (fjali njëkryegjymtyrëshe) Përbehet vetëm nga SF me SE të munguar, të pashprehur, të nënkuptuar.

Nga sa më sipër, përmbledhim se analiza në togfjalësha përfaqëson një analizë horizontale, johierarkike, të rrafshët deri në një farë mase edhe të mangët që nuk çon deri në fund zbërthimin e fjalisë në përbërës, Ndërsa, analiza e fjalisë sipas teorisë së sintagmave përfaqëson një analizë më të përshtatshme, reale, një analizë vertikale, hierarkike që vë në dukje në mënyrë të qartë lidhjet e përbërësve dhe mënyrën e vendosjes së tyre.

Gjatë analizës strukturore që mund t'i bëjmë një fjalie në sintagma, duhet të kemi parasysh dy parime të cilat janë të detyrueshme për ekzistencën e saj.

1. Parimi i Kokës - Çdo strukturë sintaksore (sintagmë) është projeksion i një njësie kokë.

2. Parimi i Binaritetit - Çdo strukturë sintaksore (sintagmë) përbëhet nga degëzimi binar.

Njësitë leksikore (fjalët) përbërëse të leksikut potencial të një gjuhe i grupojmë në Kategori Gramatikore dhe Kategori Funksionale bazuar në veçoritë semantike, morfologjike dhe sintaksore të tyre.

\section{Kategoritë Gramatikore}

Emri

Folja

Mbiemri

Parafjala

Ndajfolja

Një klasifikim i tillë praktikohet gjerësisht edhe nga përfaqësues dhe mbështetës të gramatikës tradicionale. Përkundrazi, Chomski në librin e tij “Aspekte të teorisë së sintaksës” (1965) propozon se të gjitha veçoritë gramatikore (si ato semantike, morfologjike dhe sintaksore) duhen përshkruar bazuar vetëm në një çift tiparesh binare të cilat janë $\pm \mathrm{E}$ (emëror/joemëror) dhe $\pm F$ (foljor/jofoljor) dhe në anglisht $\pm \mathrm{N}$ dhe $\pm \mathrm{F}$.

$\begin{array}{llll}\text { Emër }[+\mathrm{E} ;-\mathrm{E}] & \text { Folje }[+\mathrm{F} ;-\mathrm{F}] & \text { Mbiemër }[+\mathrm{F} ;+\mathrm{E}] & \text { Parafjala }[-\mathrm{F} ;+\mathrm{E}] \\ \text { Emër }[+\mathrm{N} ;-\mathrm{N}] & \text { Verb }[+\mathrm{V} ;-\mathrm{V}] & \text { Adjectiv }[+\mathrm{V} ;+\mathrm{N}] & \text { Preposition }[-\mathrm{V} ;+\mathrm{E}]\end{array}$

Në planin ndërtimor sintagma shfaqet si një strukturë hierarkike me përbërës të realizuar në pozicione të caktuara në varësi të të cilave ato kryejnë edhe funksionet sintaksore përkatëse. Struktura e fjalisë shprehet më qartë dhe në mënyrë hierarkike me ana të një skeme që është e njëjtë për të gjitha gjuhët, që quhet skema X-bar (dependency tree - pemë e varësisë) ${ }^{13}$. ose teoria X-bar.

${ }^{13}$ Memushaj R. Gjuhësia Gjenerative 2008, fq. 108-115

International Journal of Humanities Social Sciences and Education (IJHSSE)

Page $\mid 13$ 


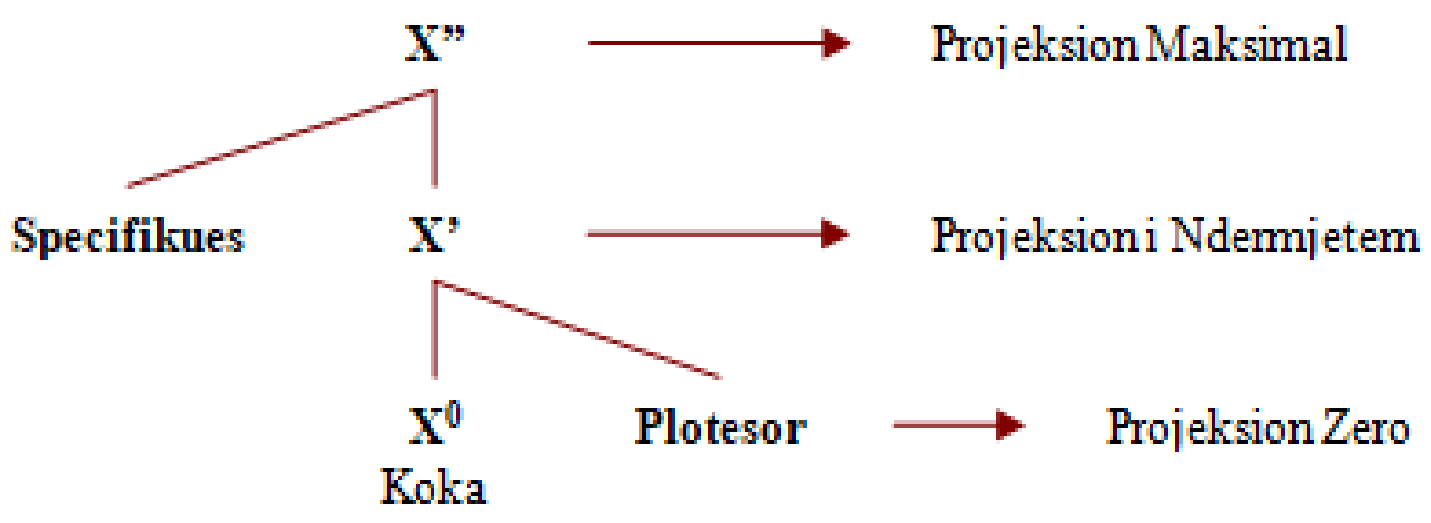

Nga kjo paraqitje skematike vihen re tre përbërës të sintagmës, specifikuesi, koka e sintagmës dhe plotësori të cilet duke u bashkuar hierarkisht japin tre nivelet e mësipërme të projektimit për çdo sintagmë. Niveli i parë ose projeksioni zero përfaqësohet nga koka e sintagmës dhe plotësori bashkimi i të cilëve formon nivelin e dytë ose projeksionin e ndërmjetëm. Niveli i tretë ose projeksioni maksimal realizohet si rezultat i bashkimit të projeksionit të ndërmjetëm me përbërësin specifikues.

Nga ky informacion i gjerë mbi karakteristikat ndërtimore të sintagmave përmbledhim:

- Koka $\left(X^{0}\right)$ përbën një element të pamungueshëm të sintagmave. Sintagma pa kokë nuk mund të ketë. Përbërësit plotësor dhe specifikues janë fakultativ, ata edhe mund të mungojnë pa patur as më të voglin ndikim mbi nivelet e projektimit të një sintagme.

- Koka përcakton llojin e sintagmës (SE, SF, SMB, SP) si dhe përzgjedh kategorinë gramatikore të plotësorit dhe specifikuesit (Në rastin e sintagmës foljore koka foljore përzgjedh si plotësor të saj një SE fakt ky që lidhet me strukturën argumentale të foljeve siç do ta shohim edhe në kapitujt në vijim ).

- Në të gjitha sintagmat me lidhje varësie dëgët mund ti përkasin një kategorie tjetër të ndryshme nga nyja (për shembull SMb "zemërgjerë nga natyra" përbërësi "nga natyra" përfaqëson një sintagmë parafjalore).

\section{REFERENCES}

[1] Adger. D.(2003), Core Syntax. A minimalist approach, Oxford University Press, ISBN-13: 9780199243709; ISBN-10: 0199243700, 82-92

[2] Akademia e Shkencave e RSh (1995), Gramatika e gjuhës shqipe II (Sintaksa), Tiranë.

[3] Alexiadou A., Heageman L., dhe Stavrou M. (2007), Noun phrase in generative perspective, Mouton de Gruyter, Berlin - New York, ISBN 978-3-11-017684-1, ISBN 978-3-11-017685.8, ISSN 0167-4331, $12-$ 20

[4] Chomsky N. (1957) Syntactic Structures, Mouton Publishers, The Hague - Paris, ISBN 902793385 5, 2635

[5] Dhima Th. (2013) Probleme të njësive sintaksore (Togfjalëshi dhe Sintagma), "Çështje të sintaksës në gjuhën shqipe”, INFBOTUES, Tiranë, ISBN-13: 978-9928-173-04-1, 9-23

[6] Dhima Th. (2013), "Rreth analizës sintaksore të fjalisë", "Çështje të sintaksës në gjuhën shqipe", INFBOTUES, Tiranë, ISBN-13: 978-9928-173-04-1, p. 23-39

[7] Dhima Th. (2013), Sintaksa e shqipes përballë zhvillimeve të reja, "Çështje të sintaksës në gjuhën shqipe", INFBOTUES, Tiranë, ISBN-13: 978-9928-173-04-1, 39-51

[8] Heageman. L.(1994), Introduction to government and binding theory, Blackwell Publishing Oxford and Cambridge, $2^{\text {nd }}$ edition, ISBN-13: 978-0631190677; ISBN-10: 0631190678, 33-40

[9] Koleci F. dhe Turano G. (2011), Hyrje në sintaksën gjenerative të shqipes, Shtepia Botuese e Librit Universitar, Tiranë, ISBN: 978-99927-0-609-1, 25-31.

[10] Memushaj R. (2008) Gjuhesia Gjenerative, Shtepia Botuese e Librit Universitar, $2^{\text {nd }}$ edition, ISBN: 97899927-0-467-7, 107-115.

[11] Memushaj R. (2008) Tri koncepte themelore të sintaksës moderne, Studime Filologjike, Nr. 1-2, 153-170

[12] Memushaj,R.(2006), Hyrje në gjuhësi, Shtepia Botuese Toena, Tiranë, 3rd edition , ISBN: 99943-1-172-7, $265-277$ 
[13] Radford. A.(2004), Minimalist Syntax. Exploring the structure of English, Cambridge University Press, Online ISBN: 9780511811319, DOI: https://doi.org/10.1017/CBO9780511811319

Citation: Phd. Joana Taci. "Sintagma: Përkufizimi, Ndërtimi Dhe Karakteristikat Dalluese Të Saj Krahasuar Me Togfjalëshin" International Journal of Humanities Social Sciences and Education (IJHSSE), vol 8, no. 8, 2021, pp. 9-15. doi: https://doi.org/10.20431/2349-0381.0808002.

Copyright: (C) 2021 Authors. This is an open-access article distributed under the terms of the Creative Commons Attribution License, which permits unrestricted use, distribution, and reproduction in any medium, provided the original author and source are credited. 